\title{
Inibidores de enzimas contra Fusarium moniliforme durante a germinação de milho
}

\author{
Ezyme inhibitors against Fusarium moniliforme in \\ corn germination
}

\author{
Patrícia Kadozawa $^{1 *}$; Edson Luis Zangrando Figueira ${ }^{2}$; Elisa Yoko Hirooka ${ }^{3}$
}

\section{Resumo}

Fusarium verticillioides (F. moniliforme Sheldon), patógeno primário de milho (Zea mays L), se destaca pela produção da fumonisina, prejudicial à saúde humana e animal. Considerando que os mecanismos naturais de defesa sejam ferramentas promissoras no controle de fitopatógenos, avaliou-se a atividade anti-F. moniliforme dos inibidores de amilase e protease presente nos híbridos AG-5011 e AG9010, durante a germinação. O perfil de atividade foi avaliado, triturando-se os grãos nos tempos $t_{0}, t_{12}$, $\mathrm{t}_{24}, \mathrm{t}_{36}, \mathrm{t}_{48}$ e $\mathrm{t}_{60}$ de horas germinação e determinou-se a atividade inibitória na farinha obtida. O inibidor de amilase aumentou com a germinação, sendo que no híbrido AG-5011 atingiu pico de atividade em $t_{60}$ (115,2 UIA/g), enquanto que no híbrido precoce AG-9010 ocorreu maior atividade em $t_{36}$ (172,8 UIA/ g). $O$ inibidor de protease diminuiu durante a germinação, ocorrendo atividade máxima entre $t_{0}$ e $t_{12}$, correspondente a 3080,5 UIP/g (AG-5011) e 2839,8 UIP/g (AG-9010). Os resultados obtidos indicaram possível desempenho de inibidores enzimáticos na germinação e mecanismo de defesa natural contra F. moniliforme no milho.

Palavras chave: Inibidores enzimáticos, F. moniliforme, germinação, milho.

\begin{abstract}
Fusarium verticillioides (F. moniliforme Sheldon) is a fumonisin producing corn (Zea mays L.) pathogen, harmful in human and animal health. Concerning the promising use of natural mechanisms of plant defense in phytopathogen control, the anti-F. moniliforme activity of amylase and protease inhibitors in corn hybrids AG-5011 and AG-9010 was evaluated during germination. The profile of inhibitory activity was followed at $t_{0}, t_{12}, t_{24}, t_{36}, t_{48}$ and $t_{60}$ of germination, determining enzyme inhibitory activities in the ground kernels. The amylase inhibitor activities increased during germination, where the hybrids AG5011 showed activity pick at $\mathrm{t}_{60}(115,2 \mathrm{UIA} / \mathrm{g})$, while the precocious hybrid AG-9010 the pick occurred at $\mathrm{t}_{36}(172,8 \mathrm{UIA} / \mathrm{g})$. The protease inhibitor activity decreased during the germination, with the maximal activity between $t_{0}$ and $t_{12}$, which corresponded to 3080,5 UIP/g (AG-5011) and 2839,8 UIP/g (AG9010). The data showed indicated probable role of enzymatic inhibitors in the plant germination and natural mechanism of defense against $F$. moniliforme in corn.
\end{abstract}

Key Words: Enzymatic inhibitors, F. Moniliforme, germination, corn.

\footnotetext{
1 Mestranda do curso de Ciência de Alimentos da Universidade Estadual de Londrina/ Endereço para correspondência: Rua Pref. Hugo Cabral, 933, Centro, Cep: 86020-110, Londrina/Paraná/Brasil. Email: patriciakadozawa@hotmail.com

2 Doutorando do curso de Ciência de Alimentos do Departamento de Alimentos e Medicamentos da Universidade Estadual de Londrina.

3 Docente do Departamento de Alimentos e Medicamentos da Universidade Estadual de Londrina.

* Autor para correspondência.
} 


\section{Introdução}

O milho constitui matéria-prima básica para a economia agropecuária internacional, destinado à alimentação animal em sistema de criação extensiva ou de confinamento (FUNDAÇÃO INSTITUTO AGRONÔMICO DO PARANÁ, 1991; GODOY, 2002 ). O caráter nutricional de excelência expõe o milho ao ataque de fitopatógenos, com destaque a Fusarium verticillioides (F. moniliforme Sheldon), um fungo responsável pela doença em espiga, colmo e raízes (MUNKVOLD; MCGEE; CARLTON, 1997), cuja ação estende-se a danos causados pelas micotoxinas. A ingestão de fumonisina, a principal micotoxina produzida por $F$. moniliforme, provoca leucoencefalomalácia eqüina, edema pulmonar em suínos, nefrotoxicidade e câncer hepático em ratos (GELDERBLOM et al., 1988). Em humanos, a toxina pode estar associada a câncer esofágico como foi descrito na China e África do Sul (NORRED; VOSS, 1994; UENO, 2000).

F. moniliforme constitui patógeno freqüente no milho, cujo caráter endofítico assintomático e residente no solo dificulta a eliminação (MUNKVOLD; DESJARDINS, 1997; RILEY; NORRED, 1999). Além de infecção endofítica (disseminação alastrada de F. moniliforme) atingindo quase a totalidade de grãos da espiga, outra via de inoculação ocorre pelo cabelo (estigma) da espiga, através de vento e insetos (MUNKVOLD; DESJARDINS, 1997).

O clima tropical propicia manutenção abundante de substrato que em cultivos sucessivos dificulta o controle de F. moniliforme, favorecendo a proliferação do patógenos micotoxigênicos (RILEY; NORRED, 1999). A pressão na seleção natural, desencadeada pela associação cultivos sucessivos / clima tropical agrava-se sob o ponto de vista ambiental, devido ao efeito drástico no ecossistema em termos de biodiversidade, expondo os patógenos a poucos inimigos naturais.

A prevenção de micotoxinas inclui estratégias na etapa de pré e pós-colheita, cuja falha no campo ou no armazenamento provoca danos econômicos, além do perigo à saúde. $\mathrm{O}$ controle eficiente de pragas e fungos através de agrotóxicos diminui estes danos (WEGULO et al., 1997; RILEY; NORRED, 1999), porém a custa de elevados prejuízos ecológicos (MCMULLEN; JONES; GALLENBERG, 1997).

A biotecnologia tem explorado novas estratégias envolvendo prevenção de micotoxinas, introduzindo milho resistente à infecção fúngica capaz de restringir o crescimento de fungos e/ou produção de toxinas (AGRICULTURAL RESEARCH SERVICE, 1997; HARA, 2000; CAMILO et al., 2000). Uma importante medida de controle se trata do manejo de culturas, impedindo a sobrevivência de $F$. moniliforme em restos de cultivos sucessivos de gramíneas. Entre as alternativas viáveis, sustentáveis e eficientes de controle destaca a prática da rotação de culturas e o preparo do solo com incorporação de restos de colheita (CALEGARI, 1997; RILEY; NORRED, 1999).

A pesquisa deve ser direcionada, visando atender tecnologias capazes de fornecer soluções efetivas de baixo custo, para o problema de micotoxinas no milho. Os mecanismos naturais de defesa apontam como solução desejável, com menor risco de contaminação secundária para o ecossistema (BETIOl, 1991). O processo minimizaria os problemas oriundos de agrotóxicos, somando-se a vantagem da utilização de componentes inerentes da planta (MOTOMURA et al., 1996). O fator atraente no processo consiste no envolvimento de componentes intrínsecos da própria matriz da matéria-prima, traduzindo-se em menor risco à saúde.

As plantas produzem metabólitos secundários aparentemente sem função direta no crescimento e desenvolvimento vegetal (TAIZ; ZEIGER, 1998). Todavia, estes componentes podem desempenhar função importante na defesa contra patógenos e herbívoros, sendo que inibidores de amilase e protease sintetizadas pelas plantas superiores bloqueiam a ação enzimática do predador (YADA; JACKMAN; SMITH, 1994). Inibidores naturais capazes de desencadear mecanismo de resistência contra fungos 
micotoxigênicos têm sido demonstrados recentemente em milho (BLANCO-LABRA et al., 1995; PUEYO; DELGADO-SALINAS, 1997; FIGUEIRA et al., 2000).

Visando contribuição ao estudo sobre a resistência natural de milho contra $F$. moniliforme, no trabalho avaliou-se a atividade antifúngica, com ênfase a inibidores de amilase e protease durante a germinação.

\section{Material e Métodos}

\section{Milho}

Sementes de cultivares AG-5011 e AG-9010 sem tratamento com fungicidas foram fornecidas pela empresa MONSANTO, unidade Uberlândia - Minas Gerais. O híbrido AG-5011 de ciclo precoce, arquitetura foliar semi-ereta, com grãos amarelos e dentados, forma espigas de bom empalhamento caracteriza-se pela tolerância a doenças foliares.O híbrido AG-9010 de ciclo hiper-precoce, arquitetura foliar ereta, grãos amarelos a alaranjados e semi duros, espigas de bom empalhamento e tolerante a doenças foliares tem sido recomendado em áreas irrigadas (AGROCERES, 2000).

\section{Fusarium moniliforme}

F. moniliforme linhagem $113 \mathrm{~F}$ foi isolado de ração de milho envolvida em intoxicação animal no Departamento de Tecnologia de Alimentos e Medicamentos. A linhagem caracterizou-se pela produção inicial de 54,21 e 87,31 ug. $\mathrm{g}^{-1}$ de fumonisina $\mathrm{B}_{1}$ $\left(\mathrm{FB}_{1}\right)$ e fumonisina $\mathrm{B}_{2}\left(\mathrm{FB}_{2}\right)$, respectivamente e foi mantida a $4^{\circ} \mathrm{C}$ com repicagem semestral em ágarbatata-dextrose (BDA).

\section{Produção de amilase e protease fúngica}

A amilase e protease de $F$. moniliforme foram produzidas em meio preparado com sobrenadante do extrato de milho verde e milho maduro (FIGUEIRA et al., 2000). Após 48 horas de incubação a $25^{\circ} \mathrm{C}$, inoculou-se $24 \mathrm{~mL}$ de cultivo em erlenmeyer de 2000 $\mathrm{mL}$ contendo $480 \mathrm{~mL}$ de meio-milho e mantido a 25 ${ }^{\circ} \mathrm{C}$ em cultivo estático por 15 dias. A fermentação foi interrompida, centrifugando o cultivo a $5000 \mathrm{xg}$ a $4{ }^{\circ} \mathrm{C}$ por 10 min e as atividades amilásica e proteásica determinadas no extrato bruto.

\section{Germinação}

As sementes de milho foram submetidas a limpeza manual, para eliminar grãos quebrados, higienizadas com hipoclorito de sódio $2 \%$ por 5 min e lavada com água estéril. Cinqüenta sementes foram dispostas simetricamente sobre dois papéis de germinação (papel de filtro $2 \mathrm{~mm}$, tamanho 38 X $28 \mathrm{~cm}$ ) previamente umedecidos. A etapa seguinte consiste em cobrir as sementes com uma folha de papel de germinação também umedecida, e dobrar o conjunto de maneira semelhante a um rolo, prendendo com elástico.

As incubações nos tempos de $0,12,24,36$, 48, e $60 \mathrm{~h}$ foram realizadas em câmara de germinação (DE LEO), controlada a $25{ }^{\circ} \mathrm{C}$ e $90 \%$ de umidade. As amostras retiradas do germinador nos intervalos foram imediatamente trituradas, obtendo-se farinha com granulometria máxima de 48 mesh. O ensaio com duas repetições consistiu de seis tratamentos correspondentes a 6 tempos de análise ( 0 a $60 \mathrm{~h})$, com intervalo de $12 \mathrm{hs}$, procedendo ensaios analítico em triplicatas das repetições.

\section{Determinação de atividade inibidora de amilase}

A atividade amilásica e de inibição foram determinadas pelo método iodométrico proposto por Wilson e Ingledew (1982), no qual uma unidade de atividade amilásica (1UIA) correspondeu à degradação de $0,1 \mathrm{mg}$ de amido em 10 min de reação, na presença de $0,667 \mathrm{mg}$ de amido.

As amostras previamente trituradas foram desengorduradas com acetona:água 1:1 (v/v) sob agitação por $15 \mathrm{~min}$, decantadas e o sobrenadante 
desprezado. O processo foi repetido 3 vezes e a amostra seca a temperatura ambiente. Para a extração de inibidor de amilase, homogeneizou-se $5 \mathrm{~g}$ de farinha desengordurada com $25 \mathrm{~mL}$ de tampão acetato de sódio $0,1 \mathrm{M} \mathrm{pH} \mathrm{6,0,} \mathrm{com} \mathrm{agitação} \mathrm{de} 400$ rpm $\left(90 \mathrm{~min}, 4^{\circ} \mathrm{C}\right)$. O sobrenadante obtido foi centrifugado a $30000 \mathrm{xg}\left(20 \mathrm{~min}, 4^{\circ} \mathrm{C}\right)$ e dialisado extensivamente contra água destilada. A seguir, 20 $\mathrm{mL}$ de solução de amilase fúngica com $50 \mathrm{~mL}$ de extrato de milho (ambos adequadamente diluídos) foi incubada por $30 \mathrm{~min}$ a $40^{\circ} \mathrm{C}$ e a atividade amilásica residual determinada, adicionando $130 \mathrm{~mL}$ de amido a $0,05 \%$ e mantido a $40{ }^{\circ} \mathrm{C}$ por $10 \mathrm{~min}$. A reação foi interrompida adicionando $140 \mathrm{~mL}$ de solução de iodo e a absorbância determinada a $650 \mathrm{~nm}$. O resultado foi expresso em unidade de inibidor de amilase (UIA.g${ }^{1}$ de milho em base seca).

\section{Determinação da atividade inibidora de protease}

A determinação da atividade inibidora de protease será efetuada utilizando-se o método de Kakade et al. (1974), modificado por Liu e Markakis (1989). A atividade da protease (1UP) será arbitrariamente definida como o aumento de 0,01 unidade de absorbância a $410 \mathrm{~nm}$ nas condições do ensaio. Em conseqüência, uma unidade inibidora de protease (1UIP) será determinada através da diferença entre as absorbâncias do padrão e da amostra, multiplicada por 100.

As amostras previamente trituradas foram desengorduradas com acetona:água 1:1 (v/v) sob agitação por $15 \mathrm{~min}$, decantadas e o sobrenadante desprezado. O processo foi repetido 3 vezes e a amostra seca a temperatura ambiente. Para a extração de inibidor de amilase, homogeneizou-se $5 \mathrm{~g}$ de farinha desengordurada com $25 \mathrm{~mL}$ de tampão acetato de sódio $0,1 \mathrm{M} \mathrm{pH} \mathrm{6,0,} \mathrm{com} \mathrm{agitação} \mathrm{de} 400 \mathrm{rpm}$ (90 $\min , 4^{\circ} \mathrm{C}$ ). $\mathrm{O}$ sobrenadante obtido foi centrifugado a $30000 \mathrm{xg}\left(20 \mathrm{~min}, 4^{\circ} \mathrm{C}\right)$ e dialisado extensivamente contra água destilada. $\mathrm{O}$ volume de $1 \mathrm{~mL}$ do extrato contendo inibidores de protease foi diluído ajustando-se o volume a $2 \mathrm{~mL}$ com água destilada deionizada. Adicionou-se $2 \mathrm{~mL}$ de solução de tripsina (concentra- ção previamente determinada por testes para fornecer $40-60 \%$ de inibição à tripsina) e foi incubado por 10 min a $37^{\circ} \mathrm{C}$. A reação foi interrompida com adição de $1 \mathrm{~mL}$ de ácido acético $30 \%$. O resultado foi calculado após determinação da densidade óptica a $410 \mathrm{~nm}$ e expresso em unidade de inibidor de protease (UIP.mg-

${ }^{1}$ de milho em base seca).

\section{Determinação do teor de proteína total}

O teor de proteína total presente nos extratos contendo os inibidores de amilase e protease, nas fases de germinação de milho, foram quantificados pelo método de Bradford (1976). Os resultados foram expressos em $\mu \mathrm{g} / \mathrm{g}$ de milho base seca.

\section{Análise estatística}

O delineamento experimental utilizado para o ensaio de germinação foi inteiramente casualizado, em esquema fatorial com 2 repetições. Nos testes laboratoriais, cada repetição foi representada por triplicatas e as médias comparadas pelo teste de Tukey $(0,05)$. Os dados foram analisados pelo programa STATISTICA versão 5.0.

\section{Resultados e Discussão}

\section{Atividade inibidora de amilase}

A atividade inibidora de amilase variou significativamente para os dois híbridos no decorrer de $60 \mathrm{~h}$ de processo germinativo $(p>0,05)$, sendo que o genótipo AG-5011 apresentou variação média de 60,5 a 115,2 UIA/g, em relação ao valor entre 46,9 e 172, 8 UIA/g no AG-9010 (Tabela 1). A Figura 1 mostra a diferença no comportamento do nível em UIA/g de atividade, durante a germinação.

No híbrido AG-5011 não ocorreu mudança significativa na quantidade de UIA nos tempos $t_{0}$ e $t_{12}$, estando os valores situados entre 73,2 a 82,9 UIA/g (Tabela 1). Analisando grãos não germinados de AG- 
5011 cultivado na região Norte do Estado do Paraná, Figueira et al. (2000) obtiveram inibição média de 16 UIA/g (safra 1997), enquanto que Pádua e Hirooka (2000) observaram 15,1 UIA/g (safra 1999). Estes dados diferiram de 73,2 UIA/g obtido no mesmo híbrido (Tabela 1), porém proveniente de safra 2000 da Empresa MONSANTO - Minas Gerais. As variações observadas no nível de inibidores em diferentes safras sugeriram diferença na síntese enzimática nos estágios que antecedem a maturidade dos grãos. I.e., influência de fatores extrínsecos marcantes com ênfase a condições climáticas, época de semeadura e local de cultivo, no nível de inibidores observadas nas três safras.

Iniciada a germinação, a atividade inibidora de amilase em AG-5011 diminuiu até $\mathrm{t}_{36}(60,5 \mathrm{UIP} / \mathrm{g})$ com pico não significativo em $\mathrm{t}_{48}(76,0 \mathrm{UIA} / \mathrm{g})$, seguido de aumento significativo, atingindo pico máximo em $t_{60}(115,2$ UIA/g). Na germinação de sementes de monocotiledôneas, as giberelinas presentes no escutelo se movem para aleurona, que consti- tui camada superficial do endosperma e promovem síntese de enzimas hidrolíticas, incluindo amilase (COPELAND; MCDONALD, 1995). O processo é dirigido por balanço nos teores de inibidores e promotores ativos, e iniciado ao estimular o promotor, que diminui a atividade dos inibidores enzimáticos. Baseado neste mecanismo, a interrupção de processo germinativo provavelmente decorre da ativação de inibidores. $\mathrm{O}$ decréscimo na atividade inibidora de amilase (Figura 1), detectada inicialmente no híbrido AG-5011 ( $\mathrm{t}_{12}$ a $\left.\mathrm{t}_{36}\right)$, liberaria a atividade de amilases, maximizando transformação do material de reserva destinada a formação da plântula. Os inibidores tenderam a aumento $\mathrm{em}_{48}$ (Figura 1), indicando início de fixação e final de germinação. A atividade inibitória de amilase denota o potencial de defesa (Figura 1), explicando a maior sensibilidade ao ataque de $F$. moniliforme nas primeiras horas de germinação no híbrido AG-5011, em função da baixa atividade inibidora.

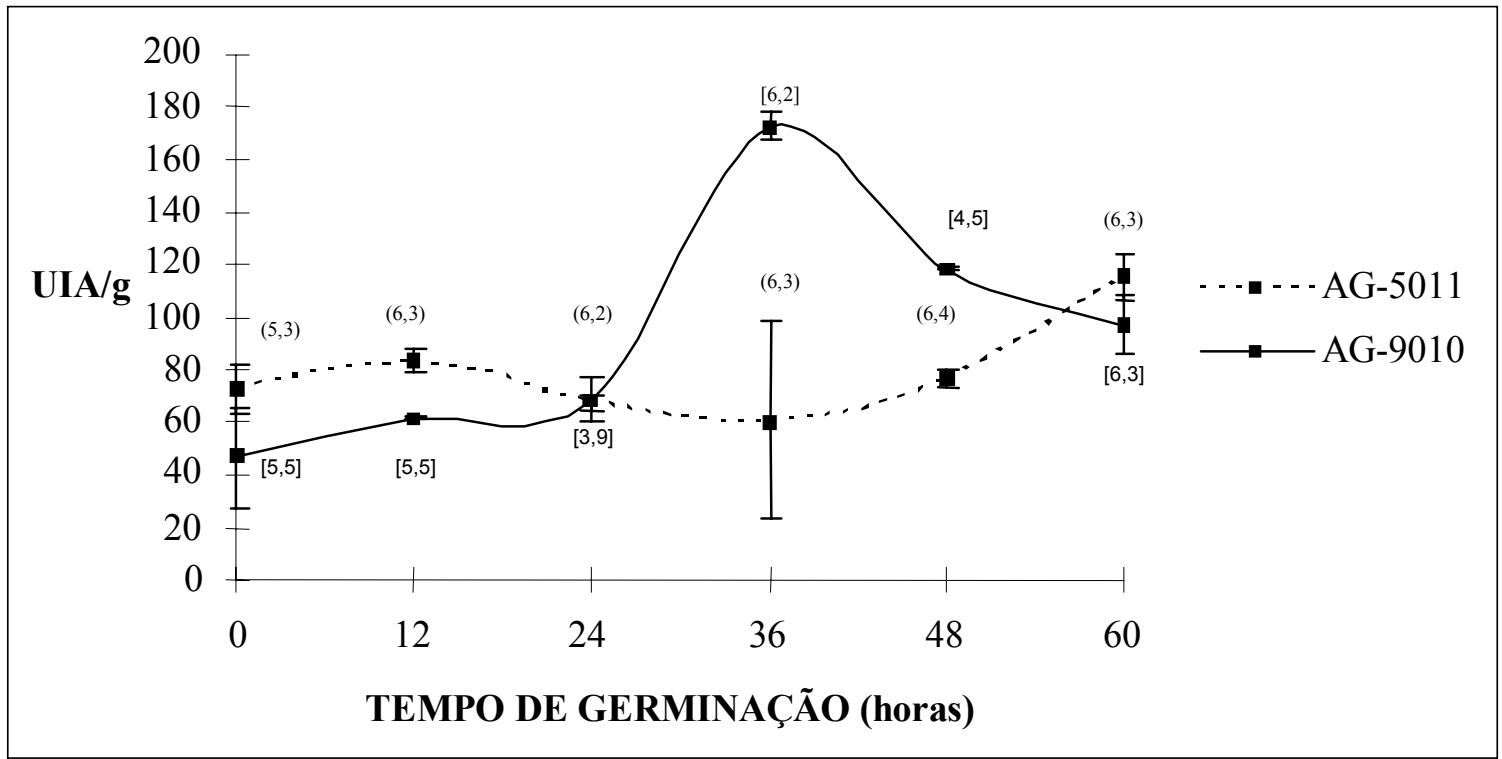

Figura 1 - Perfil de atividade inibidora de amilase na germinação de AG-5011 e AG-9010. ( ) e [ ] representam o teor de proteína total $(\mu \mathrm{g} / \mathrm{g}$ - base seca) para AG-5011 e AG-9010, respectivamente. 
A atividade inibidora de amilase no híbrido AG9010, com variação entre 46,9 e 172,8 UIA/g durante a germinação, diferiu de comportamento obtido em AG-5011, i.e., observou-se decréscimo na atividade de inibidor de amilase em $\mathrm{t}_{60}$. Nas primeiras 24 $\mathrm{h}$ de germinação, a atividade inibidora no AG-9010 variou de 46,9 a 67,7 UIA/g, sendo esta faixa menor ao detectado em AG-5011. A atividade inibidora atingiu pico de 172,8 UIA/g em ${ }_{36}$, evidenciando maior inibição que o híbrido AG-5011 no mesmo período. A concentração de inibidor de amilase no final da germinação, correspondente a $\mathrm{t}_{36}$ a $\mathrm{t}_{60}$, diminuiu gradativamente de 172,8 a 97,3 UIA/g. O pico de atividade inibidora de amilase observada em $\mathrm{t}_{36}$ (AG9010), comparada ao aumento de UIA em $t_{12}$ (AG5011) confirmou o seu caráter precoce (Figura 1).

A crescente atividade inibitória de amilase no híbrido AG-9010 até o tempo $t_{36}$ pode ser característica inerente do genótipo, que foi capaz de manter elevada concentração de inibidor. Outra hipótese seria indução na produção de inibidor no milho amostrado, decorrente de infecção natural com o patógeno. Esta hipótese fundamentou-se em Cordero, Raventós e San Segundo, (1992), que observaram acúmulo de proteínas antifúngicas de massa molecular entre 23 e 24 $\mathrm{KDa}$, concomitante com o pico de atividade ocorrida no terceiro dia de germinação $(72 \mathrm{~h})$, em sementes inoculadas com F. moniliforme.

O perfil do teor de proteínas total de AG-5011 apresentou curva com tendência semelhante à atividade inibidora de amilase, não ocorrendo o mesmo com AG-9010 (Figura 1), indicando dinamismo na síntese de diferentes proteínas durante o processo germinativo.

\section{Atividade inibidora de protease}

Considerando os resultados obtidos com inibidores de amilase em milho, na etapa seguinte analisaramse os níveis de atividade inibidora de protease, utilizando o mesmo sistema de germinação (Figura 2).

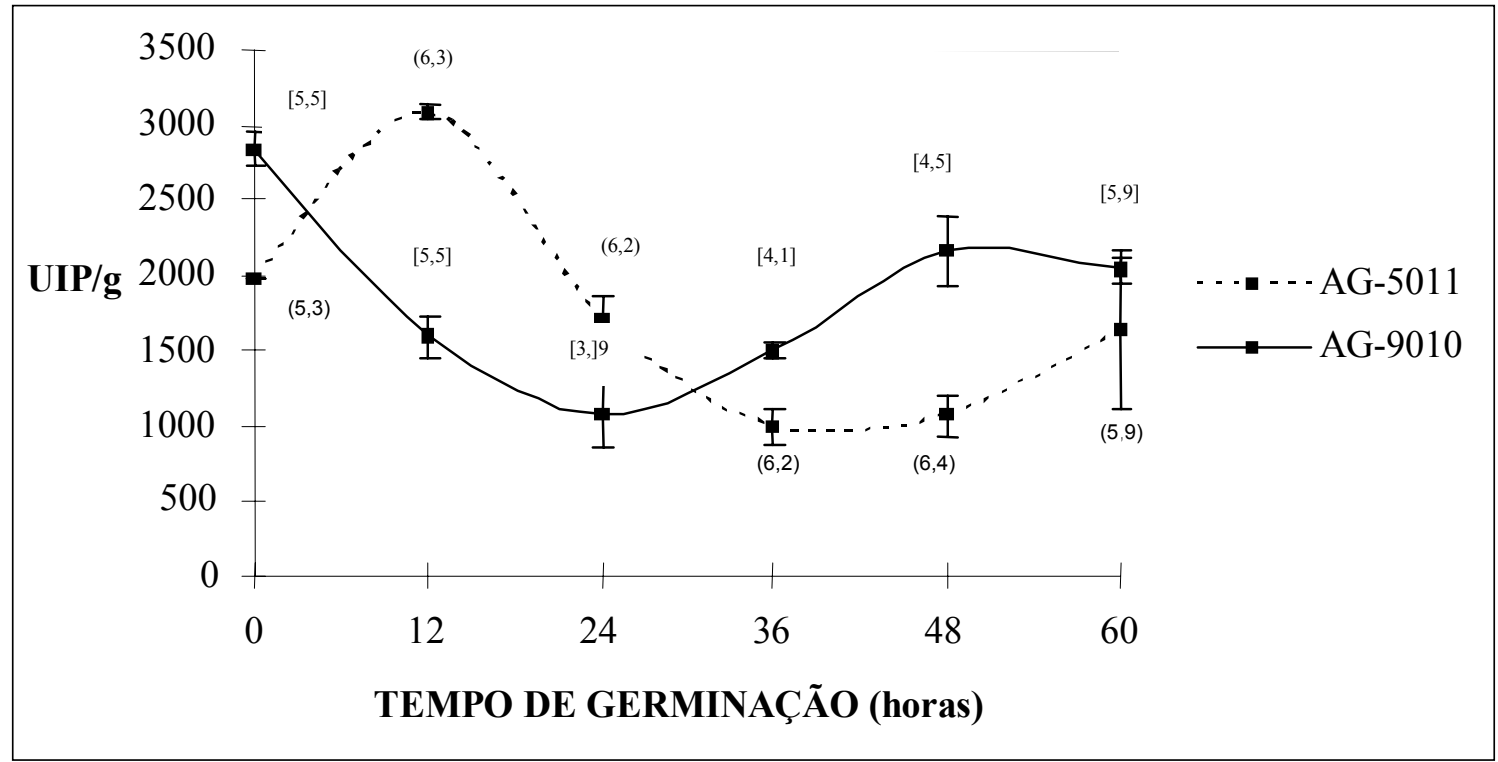

Figura 2 - Perfil da atividade de inibidor de protease durante a germinação de AG-5011 e AG-9010. ( ) e [ ] representam o teor de proteína total ( $\mu \mathrm{g} / \mathrm{g}$ - base seca) para AG-5011 e AG-9010, respectivamente. 
A atividade inibidora de protease ocorreu em maior concentração do que a atividade inibidora de amilase, em ambos os híbridos. No híbrido AG-5011, a atividade de protease variou de 984,5 a $3080,5 \mathrm{UIP} /$ g, enquanto que no híbrido AG-9010 constatou-se variação de 1063,5 a 2839,8 UIP/g.

As médias de atividade inibidora de protease nos híbridos AG-9010 e AG-5011, comparadas pelo Teste de Tukey, evidenciaram diferenças significativas em diferentes tempos de germinação, conforme perfil de comportamento ilustrado na Figura 2.

A atividade inibidora inicial no híbrido AG-5011 de 1980,0 UIP/g ( $\left.\mathrm{t}_{0}\right)$ atingiu pico máximo de 3080,5UIP/ $\mathrm{g} \mathrm{em} \mathrm{t}_{12}$, seguida de diminuição gradativa até 1062,7 $\mathrm{UIP} / \mathrm{g} \mathrm{em} \mathrm{t}_{48}$, e novo aumento de atividade em $\mathrm{t}_{60}$ (1641,4 UIP/g), porém inferior ao valor ocorrido em $\mathrm{t}_{0}$. Neste híbrido, a faixa de atividade inibidora de protease apresentou variação de 984,7 a 3080,5 UIP/ g. O perfil cinético apresentado na figura 4 mostrou que a atividade inibidora aumentou até $3080,5 \mathrm{UIP} / \mathrm{g}$ $\left(\mathrm{t}_{12}\right)$, seguida de redução drástica para 984,6 UIP/g $\left(\mathrm{t}_{36}\right)$. Após este estádio, a atividade novamente aumentou gradativamente até $1641,4 \mathrm{UIP} / \mathrm{g}\left(\mathrm{t}_{60}\right)$.

No híbrido AG-9010, a atividade decresceu para $1063,5 \mathrm{UIP} / \mathrm{g} \mathrm{em} \mathrm{t}_{24}$, seguida de aumento até 2033,9 $\mathrm{UIP} / \mathrm{g} \mathrm{em} \mathrm{t}_{60}$, porém sem recuperar a atividade inicial de 2839,8 UIP/g $\left(\mathrm{t}_{0}\right)$. A atividade de inibidor de protease de AG-9010 apresentou perfil diferente do AG-5011 (Figura 2), já que decresceu rapidamente no início da germinação para 1588,9 UIP/g $\left(\mathrm{t}_{12}\right)$, seguida de aumento gradativo até $2160,9 \mathrm{UIP} / \mathrm{g}\left(\mathrm{t}_{48}\right) \mathrm{e}$ manteve constante com 2033,9 UIP/g $\left(\mathrm{t}_{60}\right)$. O perfil cinético ocorrido em AG-5011variou entre 1063,5 e 2839,8 UIP/g (Figura 2). A curva dos níveis de inibidores de protease diferiu do perfil de proteína total em ambos híbridos de milho (Figura 2).

A literatura relata que os inibidores de protease regulam a proteólise de proteínas de reserva durante a germinação, assim como especula-se atuação na inibição de proteínas de patógenos e predadores, no contexto de mecanismo de defesa (CHEN et al., 1992; XAVIER FILHO, 1992).
Considerando a característica bifuncional dos inibidores de protease, infere-se que a atuação no mecanismo de defesa na planta seja apenas conseqüência da presença na semente (GUO et al., 1997). Os nossos resultados com o híbrido AG-5011 (Figura 2) indicaram aumento de atividade inibidora concomitantemente com o início da germinação, provavelmente decorrente de ativação dos inibidores pré-existentes. Os resultado também sugeriram maior proteção de sementes contra $F$. moniliforme no período com elevada atividade anti-protease, ou seja, em $\mathrm{t}_{12}$ onde atingiu pico com 3080,5 UIP/g (Figura 2).

Considerando que os inibidores de protease inibem proteínas hidrolíticas e controlam o fornecimento de aminoácidos livres originários de fonte protéica em estoque (COPELAND; MCDONALD, 1995), a curva cinética obtida em AG-9010 indicou indução de proteólise em $\mathrm{t}_{12}$ (redução de UIP). O fenômeno indicaria proteólise, visando abastecer suplimento de aminoácidos destinados a biossíntese no embrião em desenvolvimento. O aumento da atividade de inibidores de protease no $t_{12}$ provavelmente reduziu a atividade hidrolítica, controlando o fornecimento de fontes nitrogenadas (híbrido AG-9010). Todavia, no híbrido AG-5011 ocorreu alta atividade de inibidores de protease em $t_{12}$, que foi reduzida posteriormente, motivando continuidade de estudo sobre participação na prevenção de micotoxinas.

A resistência à infecção de $F$. moniliforme é característica desejável em milho, sendo que mecanismos de defesa devem ser melhor investigados, no sentido de fornecer subsídios para o melhoramento genético.

\section{Conclusão}

A atividade inibidora de amilase aumentou durante o processo germinativo nos híbridos AG5011 (ciclo precoce) e AG-9010 (super-precoce), não se detectando o mesmo com os inibidores de protease. O híbrido AG-9010 apresentou perfil cinético prematuro perante atividade inibidora, em relação ao AG-5011. Os resultados indicaram pos- 
sível desempenho de inibidores enzimáticos na germinação e mecanismo de defesa natural contra F. moniliforme no milho.

\section{Agradecimentos}

Ao Conselho Nacional de Pesquisa e Desenvolvimento Científico e Tecnológico (CNPq) pelo apoio financeiro e bolsas para Patrícia Kadozawa (IC), Edson Luis Zangrando Figueira (Doutorado), Maria Ângela dos Santos (AP) e Elisa Yoko Hirooka (Produtividade). A empresa MONSANTO unidade - Uberlândia/MG, através do gerente de produção Felipe Hasselmann, pelo fornecimento dos híbiridos de milho.

\section{Referências}

\section{AGRICULTURAL RESEARCH SERVICE. ARS Fusarium Workshop. Atena, set. 1997.}

AGROCERES. Região 3: São Paulo, Mato Grosso do Sul (sul) e Minas Gerais (sul). São Paulo, 2000.

BETTIOL, W. Controle biológico de doenças de plantas. Brasília: EMBRAPA, 1991.

BLANCO-LABRA, A. et al. Further characterization of the $12 \mathrm{kDa}$ protease/alpha amylase inhibitor present in maize seeds. Journal of Food Biochemistry, Trumbull, v.19, p.27-41, 1995.

BRADFORD, D. E. A rapid and sensitive method for quantification of microgan quantities of protein utilizing the principle of protein binding. Analytical Biochemistry, Orlando, v.72, p.248-254, 1976.

ALEGARI, A. Importancia de la rotación de cultivos y abonos verdes em la siembra directa. Encarnación, Paraguay: PROCISUR; MAG/CRIA, Jun. 1997. (Curso sobre Siembra Directa)

CAMILO, S. B. et al. Anti-Fusarium monilifome activity and fumonisin biodegradation by corn and silage micoflora. Brazilian Archives of Biology and Technology, Curitiba, v.43, n.2, p.159-164, 2000.

CHEN, M. S. et al. á-Amilases from three species of storage grain coleopteran and their inhibition by wheat and corn proteinaceous inhibitors. Insect Biochemistry and Molecular Biology, Kidlington, n.22, p.261-268, 1992.
COPELAND, L. O.; McDONALD, M. B. Principles of seed science and technology. $3 \mathrm{ed}$. London: Chapman and Hall, 1995,

CORDERO, M. J.; RAVENTÓS, D.; SAN SEGUNDO, B. Induction of PR proteins in germinating maize seeds infected with the fungus Fusarium moniliforme. Physiological and Molecular Plant Pathology, London, v.41, p.189-200, 1992.

FIGUEIRA, E. L. Z. et al. Fusarium moniliforme and Aspergillus flavus alpha-amilase inhibitor from corn avaliable in Paraná state, Brazil. In: INTERNACIONAL IUPAC SYMPOSIUM OF MYCOTOXIS AND PHYCOTOXINS, 10., 2000. Guarujá. Anais... Guarujá: IUPAC, 2000. p.198-198.

FUNDAÇÃO INSTITUTO AGRONÔMICO DO PARANÁ. A cultura do milho no Paraná. Londrina, 1991. (Circular, 68)

GELDERBLOM, W. C. A. et al. Fumonisins: novel micotoxins with câncer promoting activity produced by Fusarium moniliforme. Applied and Environmental Microbiology, Washington, v.51, p.376-382, 1988.

GODOY, R. C. B. Milho. Disponível em: <http:// www.pr.gov.br/celepar/SEAB> Acesso em: 6 maio 2002.

UO, B. Z. et al. Distribution of antifungal proteins in maize kernels tissues using immunochemistry. Journal of Food Protection, De Moines, v.62, n.3, p.295-299, 1997.

HARA, L. N. Interação entre Fusarium moniliforme e leveduras: antagonismo e produção de fumonisinas no milho. 2000. Dissertação (Mestrado) - Universidade Estadual de Londrina, Londrina.

KAKADE, M. L. et al. Determination of tripsin activity to soy products: a collaborative analysis of na improved procedure. Cereal Chemistry, St. Paul, v.51, p.376-382, 1974.

LIU, K.; MARKAKIS, P. An improved colorimetric method for determining antitrypitic activities in soybean products. Cereal Chemistry, St. Paul, v.66, p.415-422, 1989.

McMULLEN, M.; JONES, K.; GALLENBERG, D. Scab of wheat and barley: a reemerging disease of devastating impact. Plant Disease, St. Paul, n.81, p.1340-1348, 1997.

MOTOMURA, M. et al. Screening and isolation of antiFusarium moniliforme compounds producing microorganisms from soil and corn. Revista de Microbiologia, São Paulo, v.27, p.213-217, 1996.

MUNKVOLD, G. P.; DESJARDINS, A. E. Fumonisins in maize can we reduce their occurence? Plant Disease, St. Paul, v.81, n.6, p.556-565, 1997. 
MUNKVOLD, G. P.; McGEE, D. C.; CARLTON, W. M. Importance of different pathways for maize kernel infections by Fusarium moniliforme. Ecology and Epidemiology, v.86, n.82, p.209-217, 1997.

NORRED, W. P.; VOSS, K. A. Toxicity and role of fumonisins in animal diseases and human esophageal cancer. Jourrnal of Food Protection, De Moines, v.57. n.6, p.522-527, 1994.

\section{PAUDA E HIROOK, 2000}

PUEYO, J. J.; DELGADO-SALINAS, A. Presence of alphaamylase inhibitor in some members of the subtribe phaseolinae (phaseoleae: fabaceae). American Journal of Botany, Columbus, v.84, n.79, 1997.

RILEY, R. T.; NORRED, W. P. Mycotoxin prevention and decontamination: a case study on maize. Food, Nutrition and Agriculture, Roma, v.23, p.31-36, 1999.
TAIZ, L.; ZEIGER, E. Plant Physiology. Sunderland: Sinauer Associates, 1998.

UENO, Y. Risk of multi-exposure to natural toxins. Mycotoxins, n.50, p.13-22, 2000.

WEGULO, S. N. et al. Model economic analysis of fungicide usage in hybrid corn seed production. Plant Disease, St. Paul, n.8, p.415-422, 1997.

WILSON, J. J.; INGLEDEW, W. M. Isolation and caracterization of Schwanniomyces alluvius amylotic enzymes. Applied and Environmental Microbiology, Washington, v.44, n.2, p.301-307, 1982.

XAVIER FILHO, J. The biological roles of serine and cysteine proteinase inhibitors in plants Revista Brasileira de Fisiologia Vegetal, Brasília, v.4, n.1, p.1-6, 1992.

YADA, R. Y.; JACKMAN, R. L.; SMITH, J. L. Protein structure-function relationships in foods. Cambridge: Chapman \& Hall, 1994. 
